\title{
O CURSO DE ENFERMAGEM PEDIATRICA I NA ESCOLA DE ENFERMAGEM DA USP
}

\author{
Edelia del Pilar Neira Huerta* \\ Margareth Angelo* \\ Moneda Oliveira Ribeiro** \\ Ana Lúcia de Moraes Horta**
}

NEIRA HUERTA, E. del P.; ANGELO, M.; RIBEIRO, M.O.; HORTA, A.L. de M. O curso de Enfermagem Pediátrica I na Escola de Enfermagem da USP. Rev. Esc. Enf. USP, São Paulo, 19(3):247-262, 1985.

A partir dos motivos que levaram o grupo de docentes da disciplina Enfermagem Pediátrica da Escola de Enfermagem da USP a adotar uma nova metodologia de ensino, as autoras apresentam as atuais caracteristicas do curso Enfermagem Pediátrica I - nivel graduação, bem como a forma em que os principais momentos do curso são implementados.

\section{INTRODUÇÃO}

A aparente resistência à aprendizagem apresentada pelos alunos, manifestada principalmente através da negação dos estudantes em realizar algumas tarefas exigidas pelo Curso de Enfermagem Pediátrica I (MORAES \& PAULA ${ }^{1}$ ), aliada a observação das docentes de que, na prática profissional, os ex-alunos não estavam aplicando aquilo que lhes fora ensinado, levou o grupo de docentes dessa disciplina a profundas reflexões e a concluir que, para ocorrer aprendizagem efetiva, era necessária a existência de um clima que favorecesse a vivência de experiências significativas (RIBEIRO et alii $^{2}$ ).

Essa conclusão fez com que, a partir de 1979, o grupo de docentes optasse por utilizar a Metodologia de Ensino Centrado no Estudante, no curso de Enfermagem Pediátrica I, que é ministrado no curso de Graduação desde essa época, 20 grupos de alunos experimentaram a nova metodologia e os resultados, observados tanto nos alunos da graduação como em ex-alunos, permitem-nos afirmar que o aprendizado tem sido mais efetivo.

* Enfermeira. Mestre em Enfermagem. Professor Assistente do Departamento de Enfermagem Materno-Infantil e Psiquiátrica da Escola de Enfermagem da USP - disciplina Enfermagem Pediatrica.

** Enfermeira. Auxiliar de Ensino do Departamento de Enfermagem Materno-Infantil e Psiquíatrica da Escola de Enfermagem da USP - disciplina Enfermagem Pediátrica. 
Assim, a atitude dos estudantes tem sido mais positiva do que no métido formal: eles se interessam mais por Enfermagem Pediátrica (fato demonstrado pelo aumento de alunos cursando "Administração aplicada à Enfermagem" que optam por experiência de campo em unidades pediátricas, bem como pela procura de cursos de especialização em Énfermagem Pediátrica e de estágio voluntários na Área Pediátrica) e mostram compreender melhor as necessidades da criança hospitalizada e de sua familia. O comportamento dos alunos durante o curso, assim como os relatos verbais e escritos de suas experiências no curso, revelam mudanças de percepção, de habilidades e de atitudes, as quais evidenciam a ocorrência de aprendizagem efetiva.

Temos observado, também, que ex-alunas que vivenciaram a nova metodologia, vêm apresentando comportamentos e atitudes mais satisfatórios no desempenho de suas funções como enfermeiras de unidades pediátricas: elas demonstram inquietude por continuar aprendendo e mostram saber como fazê-lo (procuram recursos, solicitam material bibliográfico, discutem os assuntos que as motivam); demonstram também, interesse, preocupação e disponibilidade em relação à criança hospitalizada e seus pais, manifestada através de aproximação e aumento da comunicação com eles; verbalizam a vontade de provocar mudanças em sua unidade e procuram possiveis caminhos para implementá-las.

As avaliações dos alunos dos diferentes grupos, aliada à análise e reflexão de nossas percepções sobre o ocorrido em cada um desses grupos, têm fornecido elementos para aprimorar constantemente a implementação da metodologia, como também têm permitido uma melhor definição da filosofia do grupo de docentes.

Neste trabalho nos propusemos a apresentar os principais aspectos dessa filosofia, bem como o atual funcionamento do curso Enfermagem Pediátrica I - nível graduação.

\section{FILOSOFIA DO GRUPO DE DOCENTES DA DISCIPLINA} ENFERMAGEM PEDIATRICA DA ESCOLA DE ENFERMAGEM DA USP: PRINCIPAIS ASPECTOS

\section{No que acreditamos? Acreditamos que:}

- todo ser humano possui capacidades potenciais para sentir, pensar, procurar os recursos necessários e agir na solução de seus próprios problemas e no atendimento de suas necessidades;

- é possível criar um clima aceitador no qual a pessoa se sinta interiormente livre para ser, onde ela detém o poder sobre si mesma e encontra oportunidade de desenvolver todas suas capacidades;

- ninguém ensina nada a ninguém, mas que é possível facilitar a aprendizagem de alguém;

- a verdadeira aprendizagem - aprendizagem significativa abrange idéias e sentimentos, abrange a pessoa como um todo; 
- a tendência básica atualizante é a MOTIVAÇÃO; esta impele a pessoa a buscar experiências que propiciem seu crescimento;

- ninguém melhor do que a própria pessoa para avaliar a extensão e o significado de sua experiência, de seu aprendizado; e

- o hábito de escrever sobre sua própria vivência favorece o autoconhecimento, o que facilita a tomada de decisões quanto à direção da própria aprendizagem bem como a auto-avaliação.

2. O que queremos oferecer? Queremos oferecer aos alunos que cursam a disciplina uma oportunidade para uma aprendizagem cognitiva-afetiva-vivencial de Enfermagem Pediátrica e alguns recursos que possibilitem esse tipo de aprendizagem.

Devido a esta filosofia, o funcionamento do nosso curso apresenta algumas características que o fazem diferente de outros cursos.

\section{ESTRUTURA DO CURSO ENFERMAGEM PEDIÁTRICA I}

O curso de Enfermagem Pediátrica I, como qualquer outro, contém 5 elementos básicos: pessoas, interações, conteúdo, processo ou método e pressão institucional. Nossa disciplina dá mais ênfase à PESSOAS e à INTERAÇÕES, acreditando que, dessa forma lidamos de modo mais criativo e construtivo com o conteúdo e, ainda, ser uma maneira mais realista de lidar com a pressão institucional.

\section{Pessoas:}

Compreendemos que a pessoa em processo de aprendizagem, ou seja, o estudante:

- desenvolve-se segundo um ritmo próprio e a seu próprio modo, obedecendo a um fator essencial ao desenvolvimento pessoal, a motivação;

- deve ter liberdade para aprender, isto é, liberdade para perceber e encaminhar seus sentimentos, idéias, necessidades e objetivos nas diferentes experiências de aprendizagem; e

- deve sentir-se comprometido e participar ativamente de sua aprendizagem.

Para incentivar o desenvolvimento dessas características do aluno, a maior parte dos períodos do curso são centrados na pessoa do estudante.

\section{Interaçōes:}

Estas interaçōes referem-se ao interrelacionamento das pessoas no curso. Achamos que o aluno deve participar de todas as oportunidades de interrelacionamento do curso, isto é, de todos os contatos que forem programados, sejam eles da classe toda, de pequenos grupos ou indi- 
viduais, porque, em cada um deles, vemos uma oportunidade de aprendizagem.

\section{Conterido:}

A enfermagem pediátrica e os elementos que a compõem estão por aí espalhados, acontecendo o tempo todo. Nossa experiência, como enfermeiras pediátricas, nos permitiu ordenar esses elementos, segundo nossa percepção, naquilo que julgamos constante e básico em enfermagem pediátrica e que caracterizam as funções da enfermeira nessa área (Anexos 1 e 2).

Além dos aspectos relativos à criança e sua família, e das questões relacionadas à enfermagem aplicada à criança e à família, o ALUNO, em processo de aprendizagem em enfermagem pediátrica, também forma parte do conteúdo, já que o propósito deste curso não é apenas aprender sobre a matéria, mas aprender essa matéria como pessoas inteiras.

Pelas considerações acima, pensamos como objetivos para o curso os seguintes:

\section{Sensibilizar o aluno para:}

- caracterizar a criança;

- identificar as necessidades da criança que precisam ser atendidas; ambiente;

- selecionar o que pode ser executado com os recursos do meio

- determinar e executar aspectos da assistência que deseje vivenciar de acordo com seus recursos pessoais e necessidades de aprendizagem, e

- estabelecer os contatos necessários, seja com a equipe de enfermagem, equipe de saúde ou com recursos da comunidade para completar a assistência à criança e sua família.

\section{Processo ou método:}

O método diz respeito a como relacionamos conteúdo e pessoas dentro dos limites impostos pela pressão institucional.

O processo ou método do nosso curso é um em que docentes e alunos JUNTOS colaboram no planeamento e implementação das atividades que auxiliarão os estudantes na consecução de seus objetivos.

A seguir, salientaremos, entre as caracteristicas da Metodologia de Ensino Centrado no Estudante, aquelas que consideramos fundamentais para o funcionamento de nosso curso:

- responsabilidade, compartilhada, pelo processo de aprendizagem;

- motivação, como base para as experiências de aprendizagem; 
- decisões quanto à direção da própria aprendizagem;

- professor como facilitador da aprendizagem;

- auto-disciplina para alcançar os objetivos;

- abrange idéias e sentimentos;

- auto-avaliação da extensão e significado da aprendizagem.

Estas características implicam em funções para alunos e docentes.

São funções do aluno:

1. definir o que quer aprender e estabelecer seus próprios objetivos de aprendizagem de enfermagem pediátrica;

2. elaborar um plano de trabalho e levá-lo à prática;

3. utilizar os recursos disponíveis e buscar outros que complementem ou faltem;

4. colaborar ativamente com os demais na consecução dos objetivos pessoais e grupais;

5. avaliar seu próprio trabalho, extensão e significado de sua aprendizagem; e

6. cumprir todas as exigências do curso.

São funções das docentes:

1. auxiliar o aluno na identificação e esclarecimento de seus objetivos de aprendizagem em enfermagem pediátrica;

2 . organizar e tornar acessiveis recursos para o processo de aprendizagem; e

3. oferecer ao aluno um clima facilitador da aprendizagem.

\section{Pressão institucional:}

Esta refere-se aos limites que a universidade impõe e que escapam ao controle das docentes; assim, por exemplo, a universidade exige certo gênero de avaliação do desempenho do estudante e nós, docentes, temos de dar notas no final de cada curso. Em nosso curso o aluno sente a a pressão institucional em termos de exigências do curso.

Essa, entretanto, não é a única razão que nos leva a cobrar do aluno o cumprimento de algumas exigências; nós temos também uma posição pessoal em relação à avaliação do estudante: sentimo-nos responsáveis por colocar à disposição da criança, de sua familia e da comunidade colegas enfermeiras que tenham pelo menos um minimo indispensável de formação em Enfermagem Pediátrica! 
Exigências do curso:

1. folha de controle de freqüência;

2. diário de vivências no curso;

3. "contrato pessoal de trabalho";

4. contratos semanais de atividades e avaliações semanais;

5. trabalho escrito;

6. avaliação final; e

7. avaliação do curso.

\section{IMPLEMENTAÇÃO DO CURSO: PRINCIPAIS MOMENTOS}

Pelo exposto até o momento, pode-se compreender que consideramos essencial, à aprendizagem efetiva, o estabelecimento e a manutenção de um clima de respeito, aceitação, compreensão, confiança e liberdade para aprender. E este clima que nos esforçamos por estabelecer desde o início do curso, ou seja, nos empenhamos em criar para os alunos uma atmosfera de liberdade para sentir, refletir e agir.

Vemos o desenrolar da primeira semana do curso como sendo decisivo para a criação desse clima e, conseqüentemente, para o resultado da aprendizagem de Enfermagem Pediátrica.

\section{Primeira semana do curso:}

Iniciamos o curso com a apresentação dos diferentes integrantes do grupo que participará da experiência de aprendizagem em Enfermagem Pediátrica, ou seja, apresentação de alunos e docentes. Para esta apresentação, após convidar os alunos a disporem as cadeiras em círculo, é utilizada a estratégia de "apresentação um do outro", isto é, cada integrante escolhe e apresenta um membro aos demais. Antes de iniciar esta apresentação, nós docentes, informamos aos alunos o objetivo desta e, para facilitar a compreensão da estratégia, começamos por nos apresentar umas às outras.

Durante a apresentação dos alunos, esforçamo-nos por captar suas reações, sua expressão corporal, o conteúdo e significado de suas verbalizações, o tipo de linguagem utilizada (polida, etc.), como também se a classe consegue completar o círculo de apresentações ou se esta se quebra em vários círculos menores.

As informações colhidas na apresentação, cuja duração média é de 50-60 minutos, fornece-nos um primeiro conhecimento do grupo; como eles se percebem entre si e, inclusive, se é uma classe muito dividida. Essa apresentação tem sido - e é - também, um desafio para nós docentes que, a cada nova experiência, percebemo-nos mais autênticas e mais espontâneas na apresentação de uma colega. 
No final da apresentação, como acontece com a maioria das vivências do grupo, a experiência é avaliada, facilitando, desse modo, o primeiro momento de reflexão para o aluno.

A seguir, e depois de uma pausa para café, passamos ao segundo momento: a orientação ao curso. Para isto a classe divide-se por afinidade em pequenos grupos, cujo número depende do número de docentes participantes do curso, sendo que cada pequeno grupo, constituído de 6 a 9 alunos e uma docente, funciona em ambiente físico diferente. Cada aluno recebe um manual que contém todas as informaçōes sobre a estrutura e funcionamento do curso, passando, a seguir, à leitura do mesmo.

Nosso papel nesse momento concentra-se em estimular cada aluno a expressar suas reações e percepções, e a formular suas dúvidas, preocupações e receios, tentando sempre esclarecer, o melhor possivel, as nossas expectativas em relação aos estudantes, tanto durante como ao término do curso. Ainda nesse momento, recomendamos que iniciem um diário de vivências e o preenchimento da folha de controle de freqüência que, como já referido, são exigências do curso.

Na folha de controle de freqüência, impresso que é fornecido pela disiciplina, o aluno deve registrar diariamente todas as atividades que realizar, tanto as teóricas quanto as práticas, bem como o total de horas que em cada dia ele dedica a essas atividades.

o diário de vivências no curso, tem a finalidade de facilitar o contato próximo e profundo do aluno consigo mesmo e com tudo aquilo que esteja acontecendo com ele no curso; em outras palavras, a finalidade desta exigência é a de facilitar o autoconhecimento do aluno durante o curso. No diário o aluno deve registrar as diferentes atividades que realizar no decorrer da disciplina, bem como o significado pessoal que cada uma dessas atividades ou experiências teve para ele.

Ainda durante a orientação ao curso, informamos os alunos sobre a programação da primeira semana. Para facilitar a identificação de motivações e necessidades individuais de aprendizagem, que auxiliem 0 aluno na formulação de seus objetivos no curso, vários periodos da primeira semana são destinados ao contato com os principais recursos de aprendizagem à sua disposição. Assim, dois periodos dessa semana são dedicados ao contato com recursos bibliográficos, realizado com a presença das docentes que atendem às eventuais solicitações de orientação e que dão sua opinião pessoal sobre os diferentes recursos bibliográficos.

Outros periodos da primeira semana são destinados ao contato com recursos de estágio. Para isto são realizadas visitas em pequenos grupos às diferentes unidades que serão utilizadas para o aprendizado prático de Enfermagem Pediátrica. Para aqueles campos, que por motivos de de distância, ou por problemas administrativos, não permitem um contato direto, programamos palestras com enfermeiras desses campos, ou seja, oferecemos ao aluno a oportunidade de tomar contato com estes últimos recursos através da percepção e experiência dessas profissionais. 
Em cada um desses contatos recomendamos aos alunos concentrarem-se na tarefa de se perceberem na situação: o que sentem, o que pensam, que motivações emergem e, quando possivel, perceberem também o ambiente, ou seja, que se concentrem em descobrir suas necessidades e motivações em relação à criança, família e equipe. Isto tudo com a intenção de facilitar o próximo momento que é dedicado ao preenchimento do "contrato pessoal de trabalho", outra exigência da disciplina, que deverá conter as seguintes informações: objetivos de aprendizagem do aluno no curso; meios que utilizará para atingir esses objetivos; e critérios que empregará para avaliar a extensão e o significado de sua aprendizagem de Enfermagem Pediátrica.

Para facilitar o cumprimento dessa exigência, a classe é dividida em pequenos grupos cujos integrantes são escolhidos aleatoriamente pelas docentes, isto com o objetivo de misturar as 'panelinhas' e, dessa forma, evitar a influência de colegas mais próximos na definição e formulação dos objetivos individuais de aprendizagem, sendo que o motivo desta divisão é comunicado à classe. Também, com a intenção de facilitar o preenchimento do "contrato pessoal de trabalho", utilizamos perguntas abertas, relembrando as experiências de contato com os diferentes recursos de aprendizagem.

A cada resposta, esforçamo-nos por mostrar nossa compreensão; esta medida leva o aluno a maior compreensão e maior aprofundamento de suas motivações e necessidades. Ajudamos também o aluno a perceber a importância de seus motivos na definição de seus objetivos de aprendizagem.

Como resultado dessa reunião em pequeno grupo, os alunos conseguem definir os objetivos que pretendem atingir durante o curso que, em conjunto, cobrem, e até excedem aquilo que consideramos conteúdo básico ou mínimo a ser aprendido (Anexo 2). Conseguem, também, definir os meios ou recursos que utilizarão nessa aprendizagem, sendo que os apresentados mais freqüentemente nos últimos grupos são: discussão em grupo com leitura prévia do assunto, palestras, exposições dialogadas, demonstrações, seminários e, cada vez menos freqüentemente, aulas expositivas.

Também como resultado do preenchimento do "contrato pessoal de trabalho", definem os critérios que utilizarão para se avaliar no curso. Entre estes, os mais citados e utilizados pelos alunos são: quantidade e profundidade de conhecimentos adquiridos; mudanças percebidas no seu desempenho prático; segurança na assistência à criança e família; esforço dedicado à consecução dos objetivos; responsabilidade desenvolvida; interesse por continuar a aprender e a aprofundar o assunto.

A fim de facilitar o início da programacão para as semanas seguintes, o último periodo da primeira semana do curso é dedicado à realização da primeira reunião do grupo como um todo, conhecida entre nós como reunião de 'grupão'. Nesta ocasião os alunos colocam para o grupo seus objetivos individuais, bem como os meios ou recursos que os ajudarão a atingi-los. Finalmente, decidem em grupo os temas ou 
assuntos pelos quais vão começar, assim como a forma que utilizarão para tratá-los.

Temos podido constatar que os temas que invariavelmente preenchem os períodos da segunda e terceira semana do curso são:

- crescimento, desenvolvimento e necessidades da criança nas diferentes faixas etárias; familia; e

- princípios de comunicação e relacionamento com a criança e sua

- avaliação global da criança.

Os temas são desenvolvidos principalmente através de discussão em grupo, com leitura prévia orientada pelas docentes. Muitos subgrupos resolvem complementar esta aprendizagem teórica com atividades em crecher e parques infantis, tais como: observação das caracteristicas físicas e de comportamento das crianças de diferentes faixas etárias; treino de alguns cuidados como troca de fraldas, banho e administração de alimentação; aplicação de princípios de comunicação com a criança; e treino da abordagem da criança na realização do exame físico.

No fim da segunda semana é realizada nova reunião do 'grupão', destinada principalmente à troca de percepções e experiências individuais, que leva os alunos a avaliar e refletir sobre o andamento do curso. Esta reflexão ajuda-os na tomada de decisões em relação aos temas que serão abordados nas próximas semanas, em que seqüência e em que forma, ajuda-os também na escolha dos campos que utilizarão e na formação dos grupos de estágio.

Temos observado que, neste momento, as 'panelas' começam a se dividir e misturar espontaneamente, o que nos leva a acreditar na valorização e compromisso de cada aluno com seus objetivos e motivação individuais.

As atividades de campo são iniciadas na terceira semana do curso. No primeiro dia de estágio, após consultar sobre os motivos individuais que levaram cada aluno a estagiar nesse campo, proporcionamos ao aluno liberdade para se perceber na situação e, antes de finalizar esse primeiro dia de estágio, realizamos reunião de pequeno grupo com o abjetivo de facilitar-lhes o preenchimento do contrato semanal de atividades, outra das exigências do curso que deve ser cumprida no início de cada semana de estágio. Neste contrato, o aluno deve registrar seus objetivos de aprendizagem para essa semana, bem como os recursos que utilizará para atingí-los. A finalidade de cada contrato semanal é a de facilitar o aproveitamento do aluno nas atividades práticas.

Para ajudá-lo no cumprimento dessa exigência, estimulamos o aluno, através de perguntas abertas, a verbalizar suas impressões e percepções, a expressar sua reação à situação. A cada resposta mostramos a nossa compreensão para o aluno, ajudando-o, dessa forma, a compreender-se melhor. 
Os contratos semanais de atividades são estudados e analisados pelas docentes com o objetivo de organizar e providenciar para cada aluno os recursos que lhe facilitem a consecução de seus objetivos de aprendizagem para essa semana, como também para selecionar outros recursos que, segundo a experiência da docente, poderiam auxiliar o aluno na sua aprendizagem.

Durante a primeira semana de estágio, bem como nas seguintes, esforçamo-nos por comunicar, de maneira efetiva, ou seja, de maneira que seja percebido pelo aluno, nossa disponibilidade constante, nosso interesse e preocupação, nossa aceitação e compreensão; em outras palavras, empenhamo-nos em comunicar-lhe que estamos com ele no seu aprendizado.

De acordo com as necessidades identificadas nos alunos damos orientação individual ou em grupo; fazemos demonstrações de diferentes procedimentos de Enfermagem Pediátrica, das formas de abordar a criança e se comunicar com ela e com seus pais em diferentes situações; assistimos o aluno na execução de procedimentos e procuramos outros recursos, à medida que os alunos os solicitam.

Durante as semanas de estágio são, também, muito freqüentes os contatos individuais solicitados tanto por alunos como pelas docentes. Estes contatos estão destinados principalmente à verbalização das experiências do aluno para melhor autoconhecimento e autocompreensão, bem como à melhor compreensão do comportamento de desempenho do aluno por parte da docente.

Ao término de cada semana de atividades práticas, cinco no total, é realizada com o grupo de estágio reunião de pequeno grupo. Por meio de perguntas abertas ajudamos os alunos a trocarem e analisarem suas experiências de aprendizado, as quais complementamos com nossa experiência e conhecimento. Nessa reunião, como em outros momentos do curso, esforçamo-nos por compreender cada aluno e comunicar-lhe tanto essa compreensão como a nossa percepção de seu desempenho no campo de estágio e no curso como um todo. Acreditamos que, dessa forma, - aluno obtém elementos que irão facilitar sua auto-avaliação semanal, outra das exigências do curso, que eles devem entregar por escrito no fim da reunião de pequeno grupo.

$\mathrm{Na}$ avaliação semanal, solicitamos ao aluno as seguintes informações: quais e o quanto dos objetivos dessa semana conseguiu atingir; fatores que influenciaram, dificultando ou facilitando esse resultado; e mudanças ocorridas na pessoa do aluno como conseqüência dessas experiências.

Nossa intenção, ao exigir do aluno as avaliações semanais, é a de lhe facilitar a formulação de objetivos para as semanas seguintes, bem como a compreensão e treino da auto-avaliação como um processo contínuo essencial à aprendizagem efetiva.

As avaliações semanais também são estudadas e analisadas pelas docentes que, através das informações nelas contidas, aliadas à obser- 
vação do comportamento e desempenho de cada aluno, conseguem aprimorar cada vez mais a caracterização do aluno e a identificação de suas necessidades.

Cada semana finaliza com uma reunião de 'grupão', na qual os alunos trocam e aprofundam ainda mais a análise e compreendem melhor o significado de suas experiências, descobrindo, assim, a essência de suas vivências e identificando mudanças pessoais. Esta compreensão de significados e mudanças pessoais permite ao aluno a identificação de experiências significativas no curso, das quais ele poderá utilizar uma ou várias para cumprir com outra das exigências do curso: o trabalho escrito. Acreditamos que uma experiência para ser significativa deve ter a qualidade de envolvimento pessoal - o aluno "inteiro": sentimentos, idéias e vontade participando da experiência; e deve ter provocado mudanças no aluno, de percepção, de comportamento ou de atitudes.

Como conseqüência das reflexões e descobertas que caracterizam cada reunião de 'grupão', os alunos tomam novas decisões em relação a como aproveitar os próximos periodos do curso: se continuarão ou mudarão de campo de estágio; aspectos teóricos que desejam ou necessitam abordar e a forma em que o farão.

Nos últimos grupos temos percebido que os alunos atendem à nossa expectativa de entrar em contato com todos os itens ou assuntos relacionados no Anexo 2, inclusive comunicação com a criança, a família e a equipe na situação especifica de morte. Observamos, também, que grande parte dos alunos dos últimos grupos tem optado por realizar suas atividades práticas num único campo de estágio, situação esta que facilita sobremaneira nosso papel e permite continuidade, sem quebras, na assistência aos alunos.

Por acreditar que, em qualquer lugar onde se encontrem crianças hospitalizadas é possível aprender Enfermagem Pediátrica, consideramos que a situação acima não prejudica a aprendizagem dos alunos. Os princípios que fundamentam a assistência de enfermagem à criança hospitalizada em diferentes situações são comuns; por esse motivo, constantemente ajudamos os alunos a extrapolarem a aplicação desses princípios para as diferentes situaçōes.

Um único dia, em horário restrito, aquele que corresponde à reunião de 'grupão' da penúltima semana do curso, é reservado para a entrega das exigências do curso. Nessa ocasião os alunos escolhem a docente com quem querem realizar a entrevista individual de avaliação, sendo condição para a escolha ter sido acompanhado por essa docente em atividades de campo.

Duas exigências do curso ainda não foram comentadas neste trabalho. Elas são: a auto-avaliação final e a avaliação do curso. Para atender à primeira destas exigências, a auto-avaliação final, cada aluno deve comunicar por escrito, em impresso fornecido pela disciplina, a sua avaliação do seu próprio desempenho e progressos no curso. Essa 
auto-avaliação deve conter também duas notas, uma para os aspectos teóricos e outra para os práticos. As perguntas contidas no impresso de auto avaliação estão distribuídas numa seqüência especial, que acreditamos ser mais uma oportunidade para o aluno compreender e treinar a auto-avaliação como um processo contínuo.

$\mathrm{Na}$ última exigência, ou seja, na avaliação do curso, o aluno deve registrar sua reação pessoal ao curso como um todo. Incentivamos cada aluno a declarar, por escrito, com a maior honestidade possivel, o que o curso significou para ele, tanto positiva quanto negativamente, e frisamos que essa avaliação não influenciará em suas notas, oferecendo inclusive a oportunidade de entregá-la em envelope fechado, que não será aberto antes das notas finais serem publicadas. Esta exigência é, em resumo, a oportunidade para avaliar o curso, as docentes, os recurso que lhe foram oferecidos e a maneira como o curso aconteceu; oportunidade esta que vemos como mais um recurso para facilitar a compreensão, por parte do aluno, do processo ocorrido nele. Para nós esta exigência constitui um meio de avaliar os recursos que oferecemos, bem como nosso desempenho no processo de aprendizagem; é o nosso 'feed-back'.

Estudamos e analisamos o 'material' - (as 7 exigências) de cada aluno, preocupando-nos principalmente em: verificar se a carga horária é suficiente para o aluno ser aprovado; identificar o significado da(s) experiência (s) relatada(s) pelo aluno no trabalho escrito; verificar o contato do aluno com os diferentes assuntos relacionados no Anexo 2, isto, principalmente, no diário de vivências no curso; verificar coerência, ou não, entre o contrato pessoal de trabalho, os contratos e avaliações semanais e a auto-avaliação final; coerência entre objetivos e critérios de avaliação definidos no contrato pessoal de trabalho e os utilizados na auto-avaliação final; verificar se as notas atribuídas pelo aluno são condizentes, ou não, com o desempenho e compromisso demonstrados durante o curso, bem como com o crescimento pessoal e profissional registrado pelo aluno, tanto no diário de vivências no curso como no trabalho escrito e auto-avaliação.

Às dificuldades, dúvidas e problemas encontrados na leitura e análise feita por cada docente são amplamente discutidos em reunião das docentes da disciplina, que levantam, em grupo, as possiveis alternativas de solução.

Os últimos três dias do curso são dedicados à avaliação. Para este são programadas as entrevistas individuais de avaliação e uma última reunião de 'grupão'. Os objetivos da entrevista individual de avaliação são os seguintes: promover e facilitar mais um momento de reflexão em relação aos significados das diferentes experiências e contatos no curso, bem como dos significados de cada uma das exigências ao aluno; oferecer ao aluno nossa percepção tanto em relação a seu 'material' quanto a seu desempenho e progressos no curso; decidir, com o aluno, sobre as notas finais no curso; e facilitar o preparo do aluno para uma participação ativa na reuniấo de encerramento do curso. 
Esta entrevista individual de avaliação, que tem duração média de uma hora e 30 minutos, é identificada pela maioria dos alunos como uma valiosa experiência, que lhes proporciona maior autoconhecimento e que contribui ainda mais para a compreensão e aprendizado da auto-avaliação como um processo contínuo essencial à formação e ao desempenho profissional.

Vale a pena, aqui, ressaltar ser uma preocupação constante do grupo de docentes aproveitar cada experiência e cada contato, como um recurso de aprendizagem da auto-avaliação como um processo contínuo. Isto é feito através da facalitação de trocas, análise e reflexão das diferentes experiências, e fornecimento de 'feed-back' ao aluno por meio da comunicação efetiva de nossa percepção em relação a seu comportamento e desempenho.

No último dia do curso é realizada reunião de 'grupão', ocasião em que os alunos relatam suas últimas experiências, entre estas a experiência da entrevista individual de avaliação, analisam todo o ocorrido no curso e refletem sobre ele, procurando identificar os diferentes significados, tanto individuais como de grupo. Esta ocasião tampouco é desperdiçada pelas docentes que, mais uma vez, relatam aos alunos sua opinião sobre as últimas experiências, bem como o significado que, para elas próprias, teve a vivência de participar, durante 8 semanas, como mais um integrante do grupo cujo objetivo era aprender Enfermagem Pediátrica.

A forma em que o curso é realizado exige comunicação constante entre as docentes para, assim, cada uma ter conhecimento e compreensão do andamento do curso, bem como para garantir a assistência e o melhor aproveitamento possivel para cada aluno. O emprego da Metodologia de Ensino Centrado no Estudante exige, portanto, relacionamento sifinicativo entre as docentes; exige que as docentes formem uma verdadeira equipe trabalhando em atmosfera de respeito, aceitação, compreensão, liberdade e apoio mútuo; clima este que cada uma de nós empenha-se em manter.

NEIRA HUERTA, E. del P.; ANGELO, M.; RIBEIRO, M.O.; HORTA, A.L. de M. The undergraduate course of Pediatric Nursing offered at the School of Nursing of the University of São Paulo. Rev. Esc. Enf. USP, São Paulo, 19(3):247-262, 1985.

Based upon the motives that led the group of instructors of pediatric nursing to adopt a new teaching methodology, the authors present the current characteristics of the Pediatric Nursing baccalaureate course of the University of São Paulo School of Nursing as well as the form in which the course is being implemented.

\section{REFERENCIAS BIBLIOGRAFICAS}

1. MORAES, E. \& PAULA, M. do A.O. de. Como percebi a ineficiencia do ensino de Enfermagem Pediátrica no aspecto referente à assistência aos pais. Rev. Esc. Wnf. USP, São Paulo, 14(3):243-56, 1980.

2. RIBEIRO, C.A. et ali1. A disciplina Enfermagem Pediátrica: avaliação, pelos alunos, de uma nova metodologia de ensino. Rev. Esc. Eñf. USP, São Paulo, 16(2):181-92, 1982. 


\section{ANEIXO 1}

Nossa percepção do perfil da Enfermeira Pediátrica

A enfermeira pediátrica executa tarefas similares às da enfermeira geral e presta assistência à criança sadia ou doente e à sua familia, desempenhando basicamente as seguintes; funçōes:

- utilizando meios apropriados, verifica o funcionamento da criança a fim de identificar áreas de intervenção que visem à promoção de seu crescimento e desenvolvimento.

- Por 'funcionamento da criança' entendemos: 'como a criança é', ou seja, as suas capacidades (motoras, de linguagem, adaptativas e sociais), suas necessidades e a maneira como elas são atendidas.

- reconhece e compreende as manifestações de doença na criança, bem como as reações à doença e hospitalização da criança e sua família e utiliza recursios apropriados no seu atendimento nesses momentos de crise.

Para o desempenho eficiente destas funções básicas, a enfermeìra pediátrica deve possuir destreza na execução de procedimentos de enfermagem pediátrica, além de grande habilidade em técnicas de comunicação e relacionamento de ajuda. 


\section{ANEXO 2}

Conteúdo básico que facilita o tornar-se Enfermeira em Pediatria

I. PRINCIPIOS DE COMUNICAÇÃO E RELACIONAMENTO

a. criança e familia

b. equipe de saúde

II. A ENFERMEIRA E A CRIANÇA

1. O que caracteriza a crianca

a. Crescimento e Desenvolvimento: princípios, teorias e marcos. Importáncia desses conhecimentos para a enfermeira.

b. Fatores que contribuem para que uma criança seja sadia: necessidades da criança e seu atendimento.

2. Papel da enfermeira junto à crianca sadia

a. Avaliar o funcionamento da criança

1. Meios para avaliar a criança: entrevista, exame físico e aplicação de testes.

2. Importância da avaliação da criança para a assistência de enfermagem.

b. Planejar e executar ações de enfermagem que visem à promoção do crescimento e desenvolvimento da criança.

c. Relacio namento com equipe de saude para o atendimento da criança sadia.

III. A ENFERMEIRA E A CRIANÇA DOENTE

1. Aspectos sociais da doença na crianga brasileira

a. Dados estatísticos de morbidade e mortalidade infantil.

b. Fatores determinantes das doenças evitáveis na criança.

c. Recursos assistenciais para atendimento da criança doente e critérias de procura e utilização desses recursoss.

d. Porquê e quando a crlanģa é hospitalizada.

e. Atuação da enfermeira para possiveis modificações dessa realidade.

2. O impacto da doenca o da hospitalização na crianca o sua familia

a. Reações da criança e familia à doença e hospitalização.

b. Recursos essenciais para o atenäimento da criança e família durante a hospitalização da criança.

1. Ambiente físico e sua organização.

2. Comunicação aplicada a situações específicas:

- com a criança $\left\{\begin{array}{l}\text { - processo de adaptação } \\ - \text { preparo para experiências dificeis } \\ - \text { utilização do brinquedo }\end{array}\right.$ 
— com a familia $\left\{\begin{array}{l}\text { - admissão e alta } \\ - \text { mães visitantes e mães } \\ \text { acompanhantes }\end{array}\right.$
- com a equipe $\left\{\begin{array}{l}- \text { passagem de plantão } \\ - \text { prescrição de enfermagem } \\ \text { - relacionamento entre os elementos } \\ \text { da equipe }\end{array}\right.$

- comunicação com a criança, familia e equipe na situaçăo especicífica de morte.

3. Assistência de enfermagem à criança hospitalizada e à sua familia

a. Objetivos do papel da enfermeira em unidade pediátrica.

b. O papel especifico da enfermeira: aplicar metodologia científica na assistência de enfermagem.

c. Características da intervenção de enfermagem junto à criança hospitalizada:

- no atendimento das necessidades comuns da criança;

- no atendimento das necessidades da criança determinadas pela doenca e hospitalização.

d. Assisténcia de enfermagem à criança com alterações de saúde mais frequientes em nosso meio:

- alteraşōes do equilíbrio hidro-eletrolítico;

- alterações das eliminações;

- alteraçóes da nutrição; $e$

- alterações da respiração. 